\title{
EL SIMBOLISMO DEL MISTERIO. NUEVA LECTURA DE MISTERIOS DE LAS NOCHES Y LOS DÍAS DE JUAN EDUARDO ZÚÑIGA
}

\author{
THE SYMBOLISM OF THE MYSTERY. NEW READING OF \\ JUAN EDUARDO ZÚÑIGA'S MISTERIOS DE LAS NOCHES Y LOS DÍAS
}

LUIS BeLtrán AlMería

Universidad de Zaragoza

Ibeltran@unizar.es

ÁNGELES ENCINAR Saint Louis University, Madrid Campus

angeles.encinar@slu.edu

RESUMEN: La obra de Juan Eduardo Zúñiga destaca entre la de sus coetáneos y en el panorama literario actual. Con Misterios de las noches y los días (1992) dio una prueba más de su excepcionalidad. En este conjunto de relatos muy breves se sumerge en el género fantástico para reflexionar sobre las pasiones humanas, en la línea de la obra de Turguéniev. La estética del hermetismo grotesco domina estos misterios en sus dos direcciones: la romántica y la realista, según Bajtín; la fantástica y la satírica, según Kayser. El presente análisis enfoca estas ficciones bajo este prisma y se detiene en la evolución de algunos cuentos sobresalientes. En estas fabulas la unilateralidad del hermetismo pre-moderno se transforma en un pensamiento y una estética abarcadores de varios puntos de vista.

PALABRAS CLAVE: Simbolismo, misterio, hermetismo grotesco, Zúñiga y Turguéniev

ABSTRACT: Juan Eduardo Zúñiga's work stands out among that of his peers and in the current literary landscape. With Misterios de las noches y los dias (1992) he gave one more proof of his exceptionality. In this set of very short stories, he immerses himself in the fantastic genre to reflect on human passions, in the line of Turguéniev's work. The aesthetics of the grotesque hermeticism dominates these mysteries in its two directions: the romantic and the realistic, according to Bakhtin; the fantastic and satirical, according to Kayser. The present analysis 
focuses these fictions under this prism and stops at the evolution of some outstanding stories. In these fables the unilaterality of pre-modern hermeticism is transformed into a thought and an aesthetic that encompasses several points of view.

KEYWORDS: Symbolism, Mystery, Grotesque Hermeticism, Zúñiga and Turguéniev

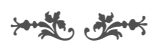

El origen de este libro fue hacerme a mí mismo un reto de si podía, quien siempre escribió con sus miras puestas en el acontecer español, imaginar episodios misteriosos o inexplicables. En fin, fue ese reto lo que hizo ir escribiendo esa especie de cuentos románticos, exagerando las características de un tiempo pasado, un lugar impreciso, etc., todo el aparato de la novela llamada gótica. Pero si se leen con atención estos cuentos se comprueba que únicamente son casos de alucinación o de sugestión de un clima poético. No hay concesiones a esa moda actual del ocultismo y el misticismo barato, que prolifera en las épocas en que las conciencias están desorientadas y no las ilumina la luz de la razón. (Peraile 1995: 26)

Las líneas precedentes demuestran hasta qué punto Juan Eduardo Zúñiga es, además de un gran escritor, un crítico perspicaz. En efecto, la literatura de masas ha desarrollado una corriente en las últimas décadas cuyos antecedentes están bien presentes en el siglo xIX. Esa moda, por utilizar el mismo término que Zúñiga, ha convertido en fenómeno de masas el ocultismo, la fantasía de ultratumba, el vampirismo, lo paranormal, las organizaciones secretas y el descubrimiento de la vida extraterrestre. Como dice, el ocultismo y el misticismo barato proliferan en las épocas de estancamiento y desorientación. A los hispanistas anglosajones les sorprende la expansión de esta literatura hermética popular a partir de la década de los ochenta del siglo pasado. Pero no han pensado en el ascenso internacional del cine popular de las mismas características, en el alcance de mitos como el del conde Drácula, en la difusión de la tradición de Halloween, de la ciencia ficción, en el éxito literario de Stephen King, o la aparición de los zombies, que no son precisamente fenómenos españoles y apuntan a algo más que a una moda pasajera. Pero, como también sugiere Zúñiga, este fenómeno admite diversos niveles estéticos, entre ellos, uno de alto nivel, que incluye tratamientos poéticos o humorísticos muy apreciados por la crítica más exigente. Sin ir más lejos, el mismo autor ha celebrado el filme de Andrei Tarkovski Stalker, una de las grandes referencias herméticas del cine actual, junto a otras algo más populares como Blade Runner o The Matrix, por mencionar solo obras de culto. En el dominio literario son muchas las referencias que pueden aducirse. Siguien- 
do con las que ha propuesto Zúñiga, no puede pasarse por alto una ya tópica, como es la obra de Kafka. ${ }^{1}$ En esta obra se conjugan lo estrictamente hermético y el humorismo. Y, en la última dimensión, hay que recordar otra de las preferencias de Zúñiga, la novela de Saramago Memorial del convento. Tienen algo en común esta y Misterios de las noches y los días, de la que nos vamos a ocupar, y es la presencia de misterios-milagros. Vayamos, ya sin preámbulos, al objeto de nuestro estudio.

\section{GÉNESIS DE MISTERIOS DE LAS NOCHES Y LOS DÍAS}

Esta obra, publicada en 1992 -con una reedición en 1993- y otra con cambios menores en 2013, recoge cuarenta relatos breves. Incluso se ha hablado de ellos como de microrrelatos. ${ }^{2}$ En Recuerdos de vida, el autor se refiere a la consideración del cuento como categoría literaria y afirma que este, "como el poema, expresa el brote de una tensión imaginativa, idéntico al arrebato de las pasiones. Y quizá de este desarrollo corto se origina la explosión que ha tenido en nuestra época el microrrelato" (2019: 87).

Para comprender el método estético de elaboración de los misterios resulta muy reveladora la lectura de la obra de Turguéniev Clara Mílich (Después de la muerte). Se trata de una novela corta (poco más de cincuenta páginas en la traducción española). Es una novela de personaje: Arátov, un hombre inútil. Sobre esta figura, tan cara a Turguéniev y Zúñiga, el ruso crea una novela de pruebas sobre las tribulaciones del protagonista. ${ }^{3}$ Se trata de una de las obras de lo que se ha llamado el Turguéniev extraño. La extrañeza consiste en que Arátov se enamora de una muerta: la Clara Mílich del título. De hecho, Turguéniev quiso titular la obra "Después de la muerte" y así figura en el manuscrito, pero el editor lo convenció para ponerle el título actual. Clara es una joven que tiene los rasgos de las mujeres libres y desequilibradas que entusiasman a ambos autores. Intenta abrirse camino como actriz. En una representación ve a Arátov y se enamora de él. Le cita en un paseo, él acude y la rechaza. Tiempo después lee en un periódico atrasado, por casualidad, que ella se ha suicidado en escena por amor. Ahí empiezan sus tormentos. Se despierta en él una pasión por Clara -que antes le desagradaba- y la fuerza de la pasión produce un amor poderoso. Arátov muere para compartirlo. La influencia de esta obra en Zúñiga es manifiesta. Las pasiones son el fundamento de sus misterios. También el misterio es el elemento

\footnotetext{
${ }^{1}$ Zúñiga ha dejado una huella de su vínculo con la obra de Kafka en el relato "No llegará el sobrino de Praga", incluido en el libro Brillan monedas oxidadas.

2 El propio autor mencionaba el término en su entrevista con Manuel Longares (2003: 39-40) También se han incluido varios de ellos en Más por menos. Antología de microrrelatos hispánicos actuales, ed. de Ángeles Encinar y Carmen Valcárcel (2011).

3 En "Mujeres leídas, soñadas" afirmaba Zúñiga: "Una palabra, una sola palabra", exclama Clara Mílich, la cantante ideada por Turguéniev cuando ha dado una cita a un hombre que le interesa y este, tímido, adusto, le responde fríamente y no se atreve a comprender y a aceptar el significado de la cita. Ella solo pide que pese a su indiferencia le diga una sola palabra de comprensión, de afecto, de ternura. Turguéniev utilizó esta frase en otros cuentos suyos quizá porque él la habría oído o por intuir que con frecuencia se decía" (Desde los bosques nevados, 2010: 26).
} 
final de Clara Mílich. En el momento de su muerte Arátov parece haber tenido trato carnal con el espectro de Clara y en la mano del joven su tía encuentra un mechón femenino que solo puede deberse a un acontecimiento sobrenatural. Varios de los misterios de Zúñiga tienen el mismo halo extraordinario, producto de la pasión. Y, sin embargo, el método de Zúñiga es justo el contrario de Turguéniev.

El suicidio de Clara es un episodio tratado de forma elusiva. Un elemento con una formidable carga dramática y grotesca -se suicida en escena- queda reducido a una noticia en un periódico y el suceso ha tenido lugar en Kazán a casi mil kilómetros de Moscú. Lo que interesa a Turguéniev es la novela de pruebas, esto es, las tribulaciones de Arátov, teñidas de un sentido cómico, porque se trata de hombre inútil y ella, una desequilibrada. Ha novelizado el caso de una actriz que se suicida en escena por un amor no correspondido. La tarea de Zúñiga es precisamente la contraria: desnovelizar el caso. Zúñiga lo reduce a lo esencial: una metamorfosis, un misterio o un milagro. Elabora cuentos, es decir, géneros fabulísticos. Aunque en sus comienzos se orientó hacia la novela -Inútiles totales, El coral y las aguas y otras novelas inéditas-, el Zúñiga de madurez prefiere las formas breves, esenciales, en la línea que teorizó Italo Calvino en sus Seis propuestas para el próximo milenio (1989). Cabe observar que esos cuentos no son piezas sueltas, independientes, sino que Zúñiga persiguió siempre insertarlos en un hilo estético, esto es, componer ciclos de cuentos. Así son sus tres volúmenes de La trilogía de la Guerra Civil o Flores de plomo.

Por otro lado, el modelo de Misterios de las noches y los días parece tomarlo Zúñiga de una obrita de la última producción de Iván Turguéniev: Pequeños poemas en prosa, publicado también como Senilia en una edición ampliada. Algunos aspectos formales apuntan en la dirección del modelo y, en términos cervantinos, puede decirse que trata de emularlo, superándolo. Aunque estas obras de Turguéniev y Zúñiga tienen un parentesco evidente, el resultado es muy distinto. Las colecciones de aquel son, desde un punto de vista estético, heterogéneas. Los cincuenta escritos de la versión última, la de Senilia, contienen sátiras menipeas, sueños, estampas idílicas, escenas alegóricas, meditaciones y alguna broma. En el caso de Zúñiga, sus relatos son misterios y su estética es homogénea. El elemento mágico es esencial. Las similitudes se reducen a la brevedad de los capítulos, al estilo de los títulos -artículo más sustantivo en la obra de Zúñiga, en Turguéniev domina esa fórmula pero admite más variedad-, y a la abundancia de los escritos: treinta y cincuenta en las dos versiones de Turguéniev, y cuarenta en la obra de Zúñiga.

Casi todos los relatos son muestras del principio que el misticismo oriental suele denominar karma: una ley universal de retribución. En términos estéticos podemos hablar de ley de la necesidad: todo en el universo está regido por unas fuerzas que Baudelaire denominó correspondences. El título, Misterios de las noches y los días, expresa muy claramente el sentido de la estética que se funda en esa ley. Todo está regido por correspondencias en la vida. Los misterios son manifestaciones de esa correlación que funciona en una dimensión dual (noche/ día es un símbolo de la dualidad de la retribución). El autor estuvo a punto de 
cambiar ese título (propuesto por la editorial) por demasiado "explícito y burdo," según nos ha confesado. Tenía otro, "Las alucinaciones", pero llegó tarde. El título frustrado hubiera seguido la ley que obliga a titular cada uno de los cuarenta relatos con la fórmula "artículo + sustantivo" ("La esfinge", "El bisabuelo", etc.). En su respuesta a la entrevista con Meliano Peraile, Zúñiga apunta el carácter de alucinaciones que tienen estos relatos, pero también señala otros aspectos no menos relevantes. El primero es su vinculación con la novela gótica. El segundo, el giro respecto a una etapa de su producción literaria orientada al "acontecer español", lo que comúnmente se ha denominado "realismo social". Merece la pena que nos detengamos brevemente en ambos aspectos.

De la novela gótica dice Zúñiga que toma dos dimensiones: el tiempo pasado y el "lugar impreciso". En verdad, esta definición tempo-espacial se ajusta mejor a Misterios que a la novela gótica. Pero resulta una inexactitud más aparente que real. De la estética gótica Zúñiga toma el pasado más o menos remoto, legendario, esto es, conectado mágicamente a la actualidad. ${ }^{4} \mathrm{Y}$ de ella toma también el espacio no familiar que no llega a ser exótico. El tiempo de Misterios es el siglo xIx. El espacio es el mundo eslavo, San Petersburgo en varias ocasiones. Ninguna de las dos localizaciones viene avalada por los relatos de forma directa. El siglo XIX aparece en forma de reiteradas alusiones a coches de caballos, duelos, muebles, relaciones serviles entre señores y criados y otras manifestaciones y costumbres propias de esa época y, sobre todo, de su literatura. ${ }^{5}$ Es la influencia de la novela gótica, de Larra -al que dedicó un estudio y un ciclo de relatos novelado, Flores de plomo-, de las obras de Turguéniev y de Chéjov, y, más en general, de la literatura rusa de ese siglo. La referencia a San Petersburgo la ha manifestado el propio Zúñiga. También nos ha indicado la noticia de la lectura de Cómo maté a Rasputín de Félix Yusupov, la versión española de El final de Rasputín, relato del crimen del místico cortesano por uno de sus asesinos. Algunos de los cuentos son versiones reducidas a su esencia mágica de anécdotas recogidas en El anillo de Pushkin, publicado unos años antes por Zúñiga. La misma referencia al anillo, esto es, a un objeto dotado de poderes sobrenaturales, es el fundamento de "El talismán", uno de los relatos de esta colección al que nos referiremos.

La fórmula de esta ambientación, pasado legendario y espacio ajeno y desconocido, es la fórmula de la novela gótica, es decir, de una forma peculiar de hermetismo grotesco. No es la primera vez que Zúñiga experimenta con esta estética. Ya lo había hecho al menos en dos ocasiones. La primera es con la

\footnotetext{
${ }^{4}$ El monje de Matthew G. Lewis, novela de referencia para el concepto de "novela gótica", tiene una geografía precisa: Madrid y otros escenarios europeos. Su tiempo no es pasado en sentido estricto. Se trata del Madrid del siglo XVIII, con la Inquisición y sus conventos. Pero lo que sí que vincula esta novela con Misterios de las noches y los días es la presencia de la magia, que tiene su fundamento en las pasiones y emociones incontrolables. Ciertos motivos de la novela de Lewis aparecen en la obra de Zúñiga: el talismán, la gitana, la estatua y, sobre todo, la pasión.

5 La nota "Una literatura romántica" que abre El anillo de Pushkin explica la relación del autor con la literatura rusa del siglo XIX: "En este libro me he propuesto recrear, como evocación de un entusiasmo juvenil, fragmentos del ámbito literario ruso, insertada la imaginación en la realidad" (1983: 9). El anillo de Pushkin es la materia de la proceden numerosos relatos de Misterios.
} 
novela El coral y las aguas, publicada en 1962 y que había recibido el premio de la revista Acento cultural en $1959 .{ }^{6}$ En aquel caso el tiempo remoto era la Antigüedad y el espacio ajeno, Grecia. La segunda ocasión es El anillo de Pushkin, ya mencionado, publicado por primera vez en 1983. Sin embargo, hay sustanciales diferencias dentro de una línea de continuidad en estas tres obras. En El coral y las aguas el recurso a esta fórmula viene exigido por la necesidad de ofrecer una versión encubierta de la Guerra Civil española. Se trata de una propuesta didáctica, que disfraza el realismo social con el realismo simbólico. No hay magia. Con El anillo de Pushkin continúa el didactismo, pero con un giro sustancial. Ya no es de carácter político sino estético. Zúñiga se distancia de las exigencias del compromiso político-social para buscar su propio camino estético, que tiene su origen en la lectura de Nido de nobles, de Turguéniev, cuando aún era un adolescente, como ha explicado en varias ocasiones. ${ }^{7}$ De hecho, El anillo de Pushkin forma parte de un ciclo con Los imposibles afectos de Iván Turguéniev y Artículos sociales de Mariano José de Larra, publicados en 1977 y 1967, respectivamente. Es el ciclo formativo de la segunda estética -y definitiva- de Zúñiga. Prueba de esto es que en 2010 publica Desde los bosques nevados. Memoria de los escritores rusos, volumen que recoge El anillo de Pushkin y Las inciertas pasiones de Iván Turguéniev.

Zúñiga abandona el didactismo social para entrar en una fase de grotesco hermético o grotesco romántico, en la senda gótica y mágica. Esa fase es paralela a la producción del ciclo madrileño: Largo noviembre de Madrid, La tierra será un paraíso y, más tarde, Capital de la gloria. Sin embargo, esta caracterización quedaría escorada si no tuviéramos en cuenta lo que separa esta obra de la literatura gótica. El aspecto diferencial que resulta más Ilamativo es la ausencia de terror, de perversidad, en la mayoría de las ficciones (una de las excepciones más notables es "La bruja"). A pesar de que las fábulas de Misterios tienen una dimensión dramática, la atmósfera en la que se desenvuelven es de carácter amable. Cuando el soldado, en la fábula homónima, agoniza se reencuentra con su madre y cree regresar a su casa. Cuando el poeta y la cantante comparten la alucinación de los dos carniceros acuchillándose, "El cuchillo", esa visión desaparece al encontrarse sus miradas. O el reencuentro complaciente entre la hija y la madre en "La diva". Las pasiones tienen en este libro, en la mayoría de los relatos, un carácter humano, no demoniaco. Lo sobrenatural, lo mágico puede y suele tener un sentido dramático, pero no demoniaco. Lo misterioso no es aquí sobrenatural sino "sobrehumano". En estas alucinaciones lo humano, la pasión, triunfa sobre las limitaciones de la existencia, sobre la rutina de lo cotidiano. La estética de Zúñiga en este dominio de lo maravilloso es la misma estética de los milagros y misterios, pero este autor le da una dimensión moderna, laica, humana.

\footnotetext{
6 Reeditada recientemente junto con su primera novela: El coral y las aguas. Inútiles totales, en la ed. de Luis Beltrán Almería y Ángeles Encinar (2019).

7 El relato "Origen de un destino", que abre el volumen El anillo de Pushkin en su primera edición, constituye el testimonio más relevante de la relación de Zúñiga con Turguéniev. En ediciones posteriores aparece al final del libro.
} 
Esta literatura supone también un giro con lo que podríamos llamar la etapa de la memoria y de la tierra natal, el ciclo de la trilogía de la Guerra Civil. La esencia de ese ciclo de la memoria queda reflejada en la nota que Zúñiga publicó en la revista Lucanor, titulada "Destellos de la memoria":

\begin{abstract}
Complejo y secreto es el origen de toda obra literaria, pero la chispa matriz que genera un relato, breve, intenso, podría equipararse a la aparición de un recuerdo no muy preciso que llega inesperado como inquietante imagen de algo vivido. Un breve episodio, unas palabras, un gesto introduce en la mente una evocación que moviliza el pensamiento siempre dispuesto a seguir las sombras.

Este destello en la memoria será el origen de un cuento: un dato aislado capaz de emocionar, que desata el deseo o la necesidad de superponer a su fugacidad mil sugerencias. Todas las fantasías, las experiencias, los rencores o amores, pueden fluir hacia esa elaboración con sus materias hechas palabras, frases, metáforas. (Zúñiga 1991: 194)
\end{abstract}

A esta certera poética habría que sumarle una premisa: que el recuerdo puede tener dos orígenes, el de la propia experiencia y el de la lectura literaria o artística. En otras palabras, puede decirse que el recuerdo puede ser primario o cultural. El ciclo de la memoria prioriza el estrato primario del recuerdo, sin prescindir de los matices culturales. El ciclo de Misterios invierte esa ecuación: la prioridad es el recuerdo cultural, sin ignorar el recuerdo primario.

\title{
2. MISTERIOS DIURNOS Y NOCTURNOS
}

Precisemos la afirmación de que la estética de Zúñiga es un hermetismo grotesco o hermetismo romántico. El grotesco moderno se ha escindido en dos direcciones: la romántica y la realista, según Bajtín; la fantástica y la satírica, según Kayser. ${ }^{8}$ Son dos fórmulas para el mismo fenómeno. La línea romántica o fantástica es la que ilustra la novela gótica y, en sentido más amplio, la literatura y el arte del enigma, de lo secreto y del tenebrismo. La línea satírica o realista, en cambio, pone el acento en el humorismo. La ilustra el carnaval moderno, lo real maravilloso. Su espíritu es transparente, alegre, regenerador. Si la primera dirección mira a lo nocturno y oscuro, la segunda es diurna y luminosa. En Misterios podemos apreciar rasgos de las dos líneas grotescas. Sin embargo, veremos que la segunda es la dominante. El título, demasiado explícito según Zúñiga, es revelador: misterios de las noches y los días.

Vayamos primero con la serie nocturna. Resulta llamativo que la primera fábula sea "La esfinge". El autor la ha elegido, quizá, porque contiene la clave de la colección de relatos: Ios misterios de la vida. ${ }^{9}$ Es una fábula nocturna, aunque

\footnotetext{
8 Estas ideas aparecen en la obra de Bajtín La cultura popular en la Edad Media y en el Renacimiento (1974) y en la obra de Kayser Lo grotesco. Su realización en literatura y pintura (1933).

${ }^{9}$ Rita Catrina Imboden sostiene que este relato "es portador de un carácter programático y puede considerarse clave de lectura para los demás cuentos del libro" (2001: 685). Explica mediante un penetrante análisis que la figura de la esfinge simboliza la "búsqueda del misterio de la existencia
} 
no es la noche su escenario. El tiempo de la fábula es la tarde, el atardecer. En cinco ocasiones se nombra ese momento. Pero hay otro tiempo, el del personaje que habla en primera persona. Ese tiempo supone toda una vida. Comienza hablando de los paseos con su madre. Prosigue con las enseñanzas del sabio profesor. Pasan los años y mueren sus parientes, tiene una amante. Y, finalmente, el secreto de la esfinge se apodera de él y su cuerpo se endurece, metamorfoseado en esfinge. Subrayemos un cambio significativo en el final entre las dos ediciones. En la de 1992 se dice: "pero dejando oír las terribles palabras que nadie entendería", mientras que en la de 2013 se ha transformado a "las terribles palabras que ahora yo entendía". La sustitución del pronombre indefinido por el personal corrobora que la metamorfosis es completa y el narrador, finalmente, es poseedor del enigma, distanciándose así de cualquier otro individuo. La "resistencia final" del cuento, en términos de Austin Wright, ${ }^{10}$ queda resuelta en la entrega definitiva. No obstante, el relato introduce la idea de la vida humana como misterio, recurrente en la colección.

La segunda fábula, "El bisabuelo", también pertenece a la serie nocturna. La lluvia de otoño y el encuentro nocturno de un joven conde con un viejo comediante en el que reconoce a su bisabuelo subrayan la nocturnidad. Nada hay de alegría o luminosidad. Incluso el mundo de los cómicos es triste y deprimente. La ilusión de un pasado familiar ilustre y elevado se revela, merced a esa visión o tal vez alucinación, penoso y opresivo.

Otra fábula nocturna es "El ángel". En ella aparece la pareja de personajes más frecuente en los relatos de Zúñiga: el hombre inútil y la mujer libre. ${ }^{11}$ Una mujer mira con deseo la estatua del ángel. Y su anhelo consigue insuflar vida en la estatua. Pero el ángel tiene los ojos vacíos y regresa a su pedestal arruinando la expectativa galante que le ofrece la mujer. Esta fábula parece tener su antecedente inmediato en el ensayo "Una estatua en Petersburgo", incluido en El anillo de Pushkin, que trata sobre esa ciudad. Aparece como un símbolo infernal, fórmula habitual en la literatura moderna que ha desplegado un género, la novela de la ciudad, donde los personajes se debaten contra la adversidad. Las imágenes de escritores como Pushkin, Odóievski, Lérmontov, Dostoievski y Maiakovski reparan en la estatua de bronce del cruel Pedro I, como metáfora del carácter perverso de la ciudad. En cierto momento de este ensayo se alude a un grupo de hombres y mujeres dados a ritos demoníacos y a orgías que contemplan la ciu-

\footnotetext{
humana" (685). Aunque reconoce que no hay nada en este relato que lo vincule al de Edipo, la esfinge, en cuanto símbolo, "sirve de soporte para exponer la evolución del sujeto" (685-686).

${ }^{10}$ En su interesante estudio "Recalcitrance in the Short Story", Austin Wright afirma que en todo cuento actúan dos fuerzas opuestas: "the force of a shaping form and the resistance of the shaped materials. [...] I call it recalcitrance or, as it resists the form, formal recalcitrance" (1989: 115-116). Esta resistencia atañe tanto al proceso de creación del autor como al de recreación del lector. Distingue dos clases fundamentales de resistencia: una que afecta al género en sí, debido a su limitada extensión, y la denomina "resistencia interna"; la otra está relacionada con el final de la historia ya que el efecto de brevedad se concentra en la conclusión, de ahí su nombre de "resistencia final" (120-127).

${ }^{11}$ Sobre la arquitectura figural de Zúñiga, basada en esta pareja del hombre inútil y la mujer libre, véase Beltrán Almería (2008: 23-24).
} 
dad "desde una altura que les comunicaba con la aguda torre del Almirantazgo [...] y con el ángel que remata la columna de Alejandro" (1983: 85). En la variación de Misterios el ángel ocupa el lugar del bronce de Pedro. El ensayo parece desdoblado en las fábulas "La esfinge" y "El ángel". Pero su sentido inquietante y cruel, ahora condensado y duplicado, ha trascendido el ámbito local.

El enamoramiento entre un hombre y una estatua es un motivo clásico en la literatura universal. Lo recordaba Mariano Baquero Goyanes cuando aludía al mito de Pigmalión y Galatea antes de realizar un excelente estudio comparativo entre tres cuentos que lo asimilan: "La muerte de la emperatriz de la China", de Rubén Darío, "La Vénus d'Ille", de Prosper Mérimée, y "The last of the Valerii", de Henry James. Si bien Baquero destaca la atención dedicada a la mirada en las tres narraciones -también sucede en la de Zúñiga y se refuerza al descubrir la mujer los ojos vacíos del ángel-, subraya, sobre todo, los diferentes tonos de los relatos; el del francés es trágico, el del inglés melancólico, y el del nicaragüense burlón y frívolo. "El ángel" coincide con la visión dramática de Mérimée. La mujer se siente desgraciada al ser rechazada y renunciará para siempre al amor; se resignará a la monotonía de la vida diaria. Como en el autor francés, prevalece "una configuración romántica" (1972: 200) ante el conflicto entre la mujer y la estatua, lo animado y lo inanimado. Lo sobresaliente en el cuento de Zúñiga es la subversión de papeles, es ella quien ama a la escultura y lo hace con vehemencia frente a la inutilidad del ángel, incapaz de corresponderla.

Las fábulas nocturnas suelen ser breves. O, al menos, más cortas que las diurnas. No es casual. El hermetismo moderno suele tender a la brevedad. Las ficciones nocturnas de Zúñiga enlazan con la tradición que la escuela de filología hispánica llama épico-lírica: los casos del Romancero, especialmente. Se trata de una estética dramática. En cambio, las diurnas tienen un carácter gozoso, que relativiza la dimensión dramática que conlleva el encuentro entre lo mágico y lo fáctico.

Las fábulas diurnas suelen tener mayor atractivo para el lector. Se trata de historias como "El secreto", "El quiosco", "El mensaje", "La esposa", "El talismán", "La bailarina", "La gitana", "La camisa", "El reloj", "La bruja", "La canción", "El embrujo" y, paradójicamente, "La noche", entre otras. Por orden de aparición, la primera es "El secreto", la tercera de la colección. A la casa de una bella joven llega un desconocido y se instala allí un tiempo. Ella se enamora, pero un día el desconocido se va. ${ }^{12}$ Todo había sido luminoso, pero a ese tiempo le sigue el tiempo de la tristeza. Hasta que un día él reaparece como una figura invisible que la acompaña de día en el jardín, por las tardes en las sesiones de piano y por la noche en su dormitorio. "A todas horas", es el regreso de la felicidad. La atmósfera victoriosa se repite en "El talismán". El oficial de húsares recibe un anillo de regalo de su amante, símbolo de su pasión, pero también objeto mágico que lo protegería de la muerte. Sucedió de este modo en las tres ocasiones predichas; sin embargo, su poder maravilloso se extendió una vez más ante la fatal

12 El origen de este relato parece la peripecia del príncipe N. y la joven Liza Ozhoguin en Diario de un hombre superfluo de Turguéniev. Zúñiga ha sustituido la apostura y elegancia del príncipe por la apariencia de un pordiosero. 
amenaza e incluso permitió la momentánea unión de los labios deseados. En "El anillo de Pushkin" el efecto protector de la joya lo experimentó el mismo poeta, su amigo Zhukovski, y el escritor Iván Turguéniev, heredero final de la joya.

Los relatos "El quiosco", "El mensaje" y "La camisa" recuperan el tópico del amor más allá de la muerte. En el primero, una mujer es acariciada en el quiosco, en medio de un parque, por una joven pareja, su jardinero y una doncella que se han apiadado de su tristeza y abandono. El marido acude escandalizado y quema el pabellón. Ella sale medio desnuda, se vuelve a contemplar las llamas y se convierte en estatua que proclama "la irreductible persistencia del amor" (2013: 36). Al metamorfosearse muere y renace. Frente a la historia bíblica de la mujer de Lot, convertida en estatua de sal como castigo, la transformación de esta en una de piedra resistente y bien pulimentada es una recompensa. En "El mensaje" un maestro de aldea tiene un especial afecto por una alumna adolescente. Ella hace un gran esfuerzo por ir a la escuela, a través de caminos cubiertos de nieve. Un día deja de ir. Más tarde el maestro se entera que ha muerto. Pero días después descubre un mensaje suyo, invitándolo a conocer su casa. A juicio del narrador, este comunicado es una ingenua y misteriosa propuesta de amor. El renacer de la primavera es también el renacer de aquella joven. En "La camisa" se trata de un amor lésbico. Una de las mujeres muere y la otra consigue revivir su erotismo acariciando la camisa de la muerta, regalo intercambiado hacía años siguiendo una costumbre gitana. La sensualidad invade el relato y la repetición de caricias y gestos practicados le permite alcanzar el éxtasis del pasado. Se trata en los tres relatos de manifestaciones amorosas que se apartan de lo convencional y que requieren libertad. ${ }^{13}$ Zúñiga ha sido precursor también en este sentido. En "Calle de Ruiz, ojos vacíos", de Largo noviembre de Madrid, presentaba la relación entre dos amigas ante el espanto del hombre que buscaba a una de ellas; y en "El último día del mundo", de La tierra será un paraíso, los dos hombres y la mujer se entregaban a las distintas opciones del amor.

La reivindicación de la libertad es la clave del relato "La gitana". El marido de la gitana ve en los ojos del amante de su mujer la imagen festiva de la gitana y sostiene un breve diálogo con esa imagen. Él le exige que se quede, pero ella le responde: "Comprende que soy gitana. Mi corazón no tiene cadenas, ni puertas cerradas, ni dueño" (2013: 73). El mismo Zúñiga explica en otros momentos de su obra esa actitud: "Ios rusos tienen la pasión de los gitanos y de sus cantos tan nostálgicamente exóticos que hacen soñar una vida libre en la naturaleza primitiva, fuera de toda sujeción y de toda ley divina y humana..." (1983: 52). Y en otra ocasión: "Los gitanos tienen un alma libre, tolerante y respetan la amistad leal y el amor como bienes transitorios, ocasionales, que mañana podrán desaparecer" (1983: 50). "La canción" tiene una orientación folclórica tradicional. Relato enmarcado en otro, el protagonista refiere una aventura de su juventud con desenlace fatal. Llama la atención la alusión a las canciones gitanas, "que expre-

13 La sensualidad y la belleza descriptiva de estos relatos con tema lésbico ("El quiosco" y "La camisa") nos hace pensar en la extraordinaria película actual Retrato de una mujer en llamas (2019), de la directora francesa Céline Sciamma, situada en el siglo XVIII. Las dos protagonistas fundamentan su futura supervivencia en el recuerdo de los momentos vividos. 
san mucho más de lo que nosotros creemos oír" (2013: 130) y, precisamente, la canción es el motivo recurrente, la fuente de pasión para el personaje. El final es radicalmente opuesto al del cuento anterior. Frente al triunfo del amor y la libertad en aquel, en este prevalece un destino aciago e inevitable, pues se castiga la elección libre de la mujer, apartada de las costumbres ancestrales de su raza.

Los relatos "La bruja" y "El embrujo" son otras muestras del papel privilegiado que el mundo gitano tiene en la obra de Zúñiga. En ambos, las gitanas están asociadas a la práctica de la magia. En el primer caso se trata de una magia funesta. La figura de Alexia aúna los polos opuestos: la seducción y la repulsa; el encantamiento fatal y poderoso es obra del deseo. En el segundo, tenemos la conversión del personaje en caballo, que recuerda al Lucio de Apuleyo (y al Lucio o el asno, atribuido a Luciano).

La serie de los misterios diurnos tiene sus símbolos específicos. La canción, el talismán y la gitana están entre los más productivos. ${ }^{14}$ También la serie nocturna los tiene, son en especial el agua y la piedra. Sin embargo, una característica del simbolismo moderno es que sus símbolos pueden intercambiar su sentido. Mientras que en "El embrujo" la magia gitana es fatal, en "La noche" el agua y la noche se convierten en instrumentos de libertad y placer.

\section{UN EJEMPLO EXCEPCIONAL: EVOLUCIÓN DE LA ESCRITURA}

Analicemos el relato "La esposa" con mayor detenimiento. En enero de 1984 apareció en la revista Ínsula un cuento de Juan Eduardo Zúñiga: "Isla violeta en las aguas plateadas de la luna". Este poético y extenso título se convirtió en 1992 en "La esposa", en consonancia con la fórmula de titular los reunidos en el volumen y, además, experimentó numerosas variaciones, formales y de contenido, acordes con la tendencia fantástica de todo el libro y con la esencialidad del lenguaje. El autor elimina adjetivos, modifica verbos, altera párrafos y suprime la explicitud. Prevalece el aura enigmática. No hay cambios en la reedición de 2013.

La ciudad y la mujer, protagonistas indudables de los ciclos de cuentos de La trilogía de la Guerra Civil y Flores de plomo (recordemos a Rosa de Madrid y a Dolores Armijo, por ejemplo, caminando por la capital), como también lo eran para los escritores rusos -lo demuestra Zúñiga en varios ensayos de Desde los bosques nevados-, lo son también en este relato, incluso con mayor fuerza en su primera versión. El inicio es casi idéntico en ambos casos, sin embargo, en la narración más reciente desaparece el tercer párrafo del texto original, donde se precisan datos para identificar a la capital de Bulgaria: "Yo preveía el pasear por ella: cúpulas doradas de viejas iglesias, Santa Nedelia, San Alejandro Nevski, el parlamento, la gran mole de la universidad, vetustos muros de Santa Sofía, acaso un monumento a un oxidado personaje ecuestre" (1984: 16). La concreta locali-

\footnotetext{
14 Los relatos de gitanos y el del caballo están inspirados en la figura de la gitana del relato de Turguéniev "El final de Chertopjánov", que forma parte de Memorias de un cazador. La esposa seducida de "El quiosco" está basado en la novela Turguéniev Canto de amor triunfante. La cruz de granates encontrada en el fondo de un cajón está tomada de Aguas primaverales.
} 
zación habría roto con el espacio desconocido de todo el conjunto de 1992, de ahí la lógica de su supresión.

Otro de los aspectos más destacables es el anonimato del escritor en la versión de 1992 frente al nombre de Ivan Nedin del cuento de 1984, repetido en cuatro ocasiones. No se corresponde con ningún escritor real, aunque puede pensarse en dos búlgaros muy admirados por Zúñiga: Dimitar Dimov, a quien conoció personalmente en Madrid y con quien entabló amistad y ficcionalizó en "Las ilusiones: el Cerro de las Balas", primer relato de La tierra será un paraíso (1989); o el poeta Peyo Yávorov, de vida turbulenta, mencionado en su libro Sofia. Los dos párrafos de introducción al personaje son muy similares con la excepción del nombre concreto:

... por aquella frágil puerta con cristales y un simple picaporte habría él entrado y salido con sus personajes a los que yo conocía por la lectura, caracteres creados o reproducidos, todos con una compleja vida profunda de humildes anhelos y fracaso. Y como otro trémulo personaje, llamé al timbre de la casa de Ivan Nedin y un hombre ya maduro... (Zúñiga 1984: 16)

... por aquella frágil puerta con cristales y un simple picaporte habría él entrado y salido con sus personajes a los que yo conocía por la lectura, creados o reflejados, pero todos con una personalidad sorprendente en sus anhelos y determinaciones. Y como otro trémulo personaje, llamé al timbre de la casa y un hombre ya maduro... (Zúñiga 1992: 48)

Hay importantes variaciones entre las dos versiones al enfocar los personajes femeninos, fundamentales en la obra de Zúñiga. Mientras en la primera se habla en general de la observación de los seres humanos, sin distinguir el género, y de la captación de los sentimientos, en la segunda se enfocan los protagonistas femeninos en particular, predominantes en todo el libro de Misterios, y así se incluye un párrafo nuevo en esta entrega: "Había concebido tipos de mujer con sus matices más variados, con su riqueza de audacia, ternura y espontaneidad, pero a la par de personajes sensibles, estaban imbuidos de libertad y responsabilidad en sus decisiones" (1992: 48). A las mujeres protagonistas en tantas ficciones rusas había dedicado un capítulo el autor madrileño en El anillo de Pushkin, titulado "Mujeres leídas, soñadas".

El narrador insiste en hablar con el escritor de un cuento que le había cautivado, donde la relación entre la pareja sobresale por la comprensión y la tolerancia. La afectación del creador le lleva a reafirmarse en la condición ficticia de lo relatado, fundamentado siempre en la imaginación. En la historia primitiva se contrasta la libertad de la fantasía con la banalidad de lo real y se concreta con una revelación profesional del autor: "Todos los hice al volver de mi trabajo en el Banco" (16). Esta concreción se anula en 1992. También se elimina el párrafo posterior, alusivo al título original, relacionado con el potente atractivo de esta ciudad sobre la voz narradora: "Solamente, como una permanencia del sueño, la montaña coronada de nieve que se alzaba junto a la ciudad -"isla violeta en las aguas plateadas de la luna", había escrito un poeta-, estaba allí, con su vago 
reflejo quizá influía en mi destino y me enviaba un mensaje misterioso" (16). No hay que olvidar la frecuente asociación entre mujer y ciudad en Zúñiga, a esta le atribuye una connotación maternal. En "Noviembre, la madre, 1936", primer relato de Largo noviembre de Madrid, se explicita: "trayendo a su conciencia la certidumbre de que una ciudad puede ser una madre" (2007: 110).

El último tercio del cuento publicado en 1992 presenta alteraciones en el orden de párrafos y dos supresiones notables que precisamos. En primer lugar, en el párrafo donde la mujer desconocida tiende sus manos al narrador sin mediar palabra alguna, de modo sencillo y espontáneo. Él interpreta el gesto como una gentileza para compensar el desinterés del escritor $y$, más destacable, le parece un símbolo de su entrega física, porque considera su posible necesidad de amor. En "Isla violeta en las aguas plateadas de la luna" las manos de la mujer contienen tres manzanas, rojas y verdes, de piel sedosa, se precisa, que el hombre recoge como una ofrenda compensatoria y establece un claro símil entre el tacto y olor de las frutas y el cuerpo de la mujer, a su juicio deseoso de afecto. Esta impresión del hablante se había anticipado al final del párrafo anterior, en la historia de 1984, cuando afirmaba: "Creí ver reunidos en ella rasgos de otras mujeres que yo había amado, rastros inolvidables de aquellas que ella ahora reencarnaba en un cuerpo, apenas entrevisto". La ilustración del relato en la revista Ínsula es la figura de una mujer ofrendando los tres frutos. La simbología manifiesta en la versión original a través de las manzanas, a modo de tentación, se transforma en un ademán más delicado después; las manos son una metonimia.

En segundo lugar, el final es diferente en las dos versiones. La deriva hacia lo fantástico se impone en la definitiva. El narrador pregunta a un conocido la identidad de la mujer que convive con el escritor y le responde que su mujer murió hace años, nadie le acompaña. Esta afirmación se hace rotunda, a pesar de la insistencia de aquel, por ello, lo terminará aceptando en las últimas frases: "No había nada real tras aquel presentimiento: tan solo una hermosa figura fantasmal a la que, sin embargo, yo había mirado con amor" (1992: 54). Por el contrario, en "Isla violeta" el yo está convencido de que el encuentro con la mujer ha sido el verdadero motivo de su visita a la ciudad, imbuido de una premonición. La conclusión, muy diferente, reafirma la conexión entre mujer y ciudad:

\footnotetext{
Al marchar, quizá para siempre, de la ciudad, antigua y moderna, vivida y soñada, ciudad que yo creía encantada por un sortilegio femenino, mis ojos buscaron de dónde este venía y vi la cumbre de la montaña nevada: sobre ella "como una tristeza sin esperanza, se esfuman, en sutil niebla, pálidas estrellas otoñales". (Zúñiga 1992: 16)
}

El texto sugiere que la belleza del paisaje circundante provoca el encantamiento y es fuente de inspiración para los autores.

"La venganza" tiene puntos en común con el cuento anterior. También está protagonizado por un escritor y una mujer y esta, asimismo, se convierte en una presencia irreal en el desarrollo de la historia. La escritura de una novela amorosa obsesiona a un autor hasta el extremo de anular a la mujer real que le visita cada día, ni siquiera su grave enfermedad le distrae de su trabajo. Le apena 
saber de su muerte, pero la noticia se desvanece frente a la tarea de finalizar su obra. El hecho fantástico se produce al releer lo escrito y comprobar la desaparición de frases y párrafos, sustituidos por espacios en blanco. El recuerdo de su amante provocó la visión de la mujer como una "diáfana transparencia" (1992: 138), una alucinación admite el personaje. Solo la dedicación auténtica a la figura intangible -ahora le dirige a ella las palabras antes dedicadas a sus personajeshace posible la reescritura del manuscrito. La preferencia del mundo ficticio al real ha provocado una consecuencia nefasta y solo el desagravio posibilita el objetivo deseado: la recuperación del texto borrado. Realidad y ficción comparten al final el mismo plano.

El color violeta está presente también en este cuento, el escritor recuerda los ojos de su amante "bordeados de anchas ojeras violetas" (1992: 137) a la par que sus relaciones durante años. La simbología de este color, asociado con frecuencia a la espiritualidad, la magia y la creatividad, cobra sentido pleno en ambos relatos.

\section{EL UMBRAL Y LA RISA}

Quizá podamos deducir del análisis de Misterios que su principal mérito sea el de fundir la dimensión fantástica con la humorística, proponiendo una versión del grotesco abierta al futuro. Como ha señalado Garrido Domínguez la dimensión fantástica de Misterios se consigue por dos métodos distintos: "el 'retorno' de seres desaparecidos y los saltos o cambios de nivel ontológico" (2017: 15). Esos recursos -Garrido Domínguez los llama manifestaciones- pueden decantarse bien por la dimensión nocturna o bien por la diurna. Pero ambas se fundan en la fuerza de la pasión, en alucinaciones -como prefiere decir Zúñiga-, esto es, en el despliegue de las fuerzas humanas más poderosas, capaces de trascender las limitaciones de lo inmanente. Esta noción de la trascendencia nos sitúa en el eje del grotesco. En términos de Bajtín, la fantasía tradicional popular es una fantasía realista porque "trabaja en la vastedad del espacio y del tiempo, y la utiliza con amplitud y profundidad. Esta fantasía se apoya en las posibilidades reales del crecimiento humano [...] necesidades y potencias del hombre, de exigencias eternas, nunca eliminables, de la naturaleza humana real" (2019: 346).

Esa fantasía realista ha sido sometida a un tratamiento especial. Consiste en borrar todo aquello que puede considerarse superfluo, innecesario. La técnica del borrado tiene el sello indeleble del hermetismo, que borra o difumina para conseguir crear escenarios donde pueda representarse lo extraordinario, lo mágico y lo misterioso (aparece de modo explícito en "La venganza"). Pero a diferencia de otros sfumatos, el borrado de Zúñiga es tan radical que deja el relato en lo mínimo esencial, a veces, impenetrable. Lo que queda es el umbral, que, siguiendo a Bajtín, es el momento de la crisis y la ruptura vital, la decisión que modifica la vida. Este momento es siempre metafórico y simbólico (Bajtín 2019: 434). Es decisivo, no tiene duración y desborda el marco biográfico del personaje. Se trata del tiempo de misterios y carnavales. 
El resultado de la reducción al momento decisivo es una estética híbrida, serio-cómica, jocoseria, que tiene dos caras, como Jano, así se representa a este dios de la mitología romana. Puede mirar a la dimensión dramática y entonces tenemos los misterios nocturnos o puede mirar a la dimensión alegre y entonces tendremos los misterios gozosos, diurnos.

Este análisis conlleva una contradicción: la dimensión del hermetismo y su compatibilidad con el humorismo. El borrado hermético produce una inclinación al dogmatismo: solo es posible un punto de vista. Ese punto de vista implica dos posiciones polares: el bien absoluto y el mal absoluto. Algo de esto hay en la primera etapa de Zúñiga. Sin embargo, la apertura hermética que se aprecia en este período produce un efecto inverso. No se da, sobre todo, en los relatos de los misterios diurnos. En estas fabulas desaparece la unilateralidad del hermetismo culto pre-moderno que es liquidado por un pensamiento y una estética abarcadores de varios puntos de vista. Esa posibilidad queda patente por la presencia de lo sobrenatural, abierto a los límites de lo fáctico. Por tanto, además del carácter gozoso, supone, al mismo tiempo, la sustitución de un pensamiento dogmático por un pensamiento abierto.

\section{OBRAS CITADAS}

Bajtín, Mijaíl M. (1974): La cultura popular en la Edad Media y en el Renacimiento. El contexto de François Rabelais. Trad. Julio Forcat y César Conroy. Barcelona, Barral.

(2019): La novela como género literario. Trad. Carlos Ginés Orta. Ed. Luis Beltrán Almería. Zaragoza/Santander/Heredia, Prensas de la Universidad de Zaragoza / Real Sociedad Menéndez / Pelayo / Editorial Universidad Nacional.

Baquero Goyanes, Mariano (1972): "El hombre y la estatua (A propósito de un cuento de Rubén Darío". En: Temas, formas y tonos literarios. Madrid, Prensa española, pp. 189-209.

Beltrán Almería, Luis (2008): El simbolismo de Juan Eduardo Zúñiga. Bellcaire d'Empordà, Edicions Vitel.la.

Encinar, Ángeles; y Valcárcel, Carmen (eds.) (2011): Más por menos. Antología de microrrelatos hispánicos actuales. Madrid, Sial.

Garrido Domínguez, Antonio (2017): "Magia y fantasía en Misterios de las noches y los días de Juan Eduardo Zúñiga", Hispanófila, n. ${ }^{\circ} 179$, pp. 15-22.

Imboden, Rita Catrina (2001): "'La esfinge' en Misterios de las noches y los días, de Juan Eduardo Zúñiga". En José Romera Castillo y Francisco Gutiérrez Carbajo (eds.): El cuento en la década de los noventa. Madrid, Visor, pp. 683-691.

Kayser, Wolfgang (2010): Lo grotesco: su realización en literatura y pintura. Trad. J. A. García Román. Madrid, Antonio Machado Libros.

Longares, Manuel (2003): "Una charla con Juan Eduardo Zúñiga", Quimera, n. 227, pp. 36-40.

Peraile, Meliano (1995): "Diálogos con Juan Eduardo Zúñiga", Asociación Colegial de Escritores, n. 27 , pp. 25-27. 
Wright, Austin M. (1989): "Recalcitrance in the Short Story". En Susan Lohafer y Jo Ellyn Clarey (eds.): Short Story Theory at a Crossroads. Baton Rouge / Londres, Louisiana State University Press, pp. 115-129.

Zúñiga, Juan Eduardo (1983): El anillo de Pushkin. Barcelona, Bruguera.

— (1984): "Isla violeta en las aguas plateadas de la luna", Ínsula, n. ${ }^{\circ} 446$, p. 16.

- (1991): "Destellos de la memoria", Lucanor, n. ${ }^{\circ}$ 6, p. 194.

- (1992): Misterios de las noches y los días. Madrid, Alfaguara. Reedición en Barcelona, Galaxia Gutenberg, 2013.

- (2007): Largo noviembre de Madrid. La tierra será un paraíso. Capital de la gloria. Ed. Israel Prados. Madrid, Cátedra.

_ (2010): Brillan monedas oxidadas. Barcelona, Galaxia Gutenberg.

_ (2010): Desde los bosques nevados. Barcelona, Galaxia Gutenberg.

_ (2019): Inútiles totales. El coral y las aguas. Eds. Luis Beltrán Almería y Ángeles Encinar. Madrid, Cátedra.

(2019): Recuerdos de vida. Barcelona, Galaxia Gutenberg. 